\title{
COMPARE THE BEHAVIOR FACTOR OF THE ULTIMATE RESISTANCE OF MOMENT FRAME, PLAIN AND PERFORATED STEEL PLATE SHEAR WALLS, AND BUCKLING RESTRAINED BRACE AS YIELDING METAL DAMPER
}

\author{
Hamid Reza Ashrafi', Kasra Shahbazian', Shaahin Bidmeshki', \\ Somaye Yaghooti ${ }^{1}$, Peyman Beiranvand ${ }^{1}$ \\ 1 Technical and Engineering Faculty, Razi University, Kermanshah, Iran, e-mail: h_r_ashrafi@yahoo.com; \\ peyman51471366@gmail.com
}

Received: 2015.12.15

Accepted: 2016.02.01

Published: 2016.03 .01

\begin{abstract}
Steel moment frame systems, steel plate shear walls and also buckling restrained brace (BRB) are considered as the most widely used seismic resistant systems of the world. Firstly, in this research, in order to validate the finite element models, the tested sample of steel plate shear walls of 4 floors at the University of Alberta, Canada, and the tested sample of buckling restrained brace at the University of Berkeley California, with the software ABAQUS 6.10-1 were used. Then, the obtained results of the test and analysis have been compared. The confirmed models have been used for the analysis of two-dimensional frame of plain and perforated steel plate shear walls with a regular pattern of positing holes in the screen, buckling restrained brace and moment frame of 4 floors.
\end{abstract}

Keywords: behavior factor, ultimate resistance, steel plate shear walls, buckling restrained brace.

\section{INTRODUCTION}

Many structures during a moderate and severe earthquake enter the inelastic range, so in order to perform a structural design, one must use the inelastic analysis. Due to the ease of elastic analysis as well as the complexity and time-consumption of non-elastic analysis, regulations suggest factors to reduce lateral force of earthquake. Therefore, different ways to counter the lateral loads caused by earthquake are presented. These methods include: steel moment frame, all kinds of braces, shear walls, and so on.

The first research was conducted on thin nothard steel plate shear walls in 1983 by Torbren et al. They provided an analytical model for investigating the shear resistance of thin not-hard steel plate shear walls [1].

Roberts and Saburi-Ghomi (1992) performed a series of alternating quasi-static load tests on not-hard steel plate shear panels with a central circular opening. According to their recommendations, resistance (Vyp, perf) and hardness of perforated panels (Kperf) can be estimated as conservative by applying a linear reduction factor in resistance ( $V y p)$ and hardness of similar solid panel (Kpanel) [2].

The first research was conducted in 1973 by Vakabayashy et al. in the field of buckling restrained brace (BRB). They have proposed a system in which braces of steel plate were placed into the two plates of pre-stressed reinforced concrete. Several tests that were performed on this system showed that although the braces resistance in a little pressure is in stretch more than their resistance, but the cyclic behavior of the system is symmetrical and stable [3].

Sabelli (2001) performed a statistical study on the response of buckling restrained braced structures and braced structures of common convergent. Buckling restrained braced frames were designed by behavior factor of 6 and also by be- 
havior factor of 8 . The results of this analysis showed that the behavior of buckling restrained braced frame in most cases is better than a common converged braced frame. Also, responses of buckling restrained brace system are not sensitive to the behavior factor [4].

Unfortunately, in regulations 2800 no information on the behavior factor and steel plate shear wall resistance and buckling restrained brace is available. So in this article, it is considered to determine the parameters in two types of systems: lateral as well as moment frame (whose behavior factor is included in regulations 2800) and their comparison. For this purpose, the finite element software ABAQUS6.10-1 is used. To validate the presented model in this application, the results of conducted experimental work by Draiver and co-workers used a sample of steel plate shear wall, and reviewed the results by Cameroon Black et al. on a sample of 1-99 braced buckling.

\section{THE INTRODUCTION OF STUDIED LATERAL SYSTEMS}

\section{Steel Plate Shear Walls}

Steel plate shear walls (SPSW) are considered a resistant system to lateral forces such as wind and earthquake forces. Steel plate shear wall includes vertical steel plate called filler plate that connects to beams and plates surrounding border columns in the total height of the frame. Filler plates can be used as hard or not hard. Rigid or simple connections can also be used in connecting the beam to the column. If the design of steel plate shear wall is performed correctly, this type of system, with ductility, will have sufficient hardness and the ability for absorbing a lot of energy [5].

\section{Buckling Restrained Brace}

Many conventional convergent bracing behavioral deficits, resulting from the difference between compressive and tensile capacity of the braces, and reducing their resistance under cyclic loading. Therefore, in order to achieve a behavior of an ideal Elasto, a lot of research has been done to improve braces. To achieve this goal it was necessary to use appropriate mechanism to prevent the buckling compression brace and provide the possibility of steel pressure. For this purpose, the encapsulation of a ductile metal core was used in a volume of enclosed concrete in a metal membrane. The main function of the damper is that in order keep pressure in it, a steel core buckling is prevented. In this way, the energy absorbed by the membrane increases.

In order to prevent buckling of the core, it is placed in a filled steel sheath with concrete. The system needs to provide a sliding surface or discontinuity layer between the metal core and surrounding concrete. The purpose of this system is that the bracing force just is tolerated by steel core. It should be designed with the abovementioned sliding layer geometry and materials in such a way that provides the possibility of a relative movement between the steel and concrete core that is caused due to Poisson effect. As a result, while preventing local buckling of the core, the possibility of its submission in the loading pressure is provided. Concrete and steel sheath provide hardness and necessary moment resistance to prevent the total buckling of brace and provide the possibility of load-bearing by steel core to the surrender without a significant reduction in hardness and resistance of brace during loading cycles. Concrete and steel sheath also prevent the local buckling of the core [6].

\section{Moment frame}

Moment frame includes a set of beams and columns, which are connected to each other with a rigid connection. Resistance to lateral loads is provided first by moment frame behavior, the creation of bending moment and shears force in the connections and frame members. Given the nature of the rigid beam-column connections, due to lateral change of moment frame, bending moment will be created in beams and columns. So the rigidity and moment resistance of frame members have a significant contribution in harden and lateral resistance of total frame.

\section{Behavior factor}

Structure behavior factor is a factor which consists of inelastic behavior of structure and indicates the hidden resistance of structure in the inelastic stage. For this reason, the required structure resistance is calculated from the dividing of required resistance in a totally elastic mode on this factor. Behavior factor or reduction factor of force depends on such parameters as ductility factor, main alternation period of structure, structure damping factor, soil characteristics, earthquake 
characteristics, load-deformation behavior, increasing resistance factor, participation of higher modes and confidence factor of designing.

Usually, behavior factor for different systems of structure is estimated experimentally and based on field observation of buildings performance in the past earthquakes. Since the early 1980's, researchers sought to analyze the factor to its formation factors. Many laboratory studies were carried out including the research conducted in Applied Technology Council (ATC).

Until now, researchers have used different methods for calculating the behavior. By comparing these methods one can divide them into two groups. One method is American researchers and other European researchers. Generally US methods have simpler theoretical foundations and practical applications. While European methods have more complex analytics and theoretical foundations, their use in practice is more difficult. US researchers' methods include: Freeman capacity spectrum method and Yang ductility factor. European researchers' methods also include the theory of ductility and energy method.

In this study, Yang's method was used to calculate the behavior factor. In Figures 1 and 2, relevant parameters and Pushovar curve with two linear graphs are shown.

According to this method, behavior factor is calculated based on the following formula:

$$
R=R_{\mu} \times \Omega \times \mathrm{Y}
$$

where: $R_{\mu}-$ is ductility reduction factor,

$\Omega$-is increased resistance factor,

$\mathrm{Y}-$ is permitted stress factor.

Each of these parameters are described in the work [7].

\section{Ductility reduction factor}

Inelastic deformation capacity of structures is expressed with the help of their ductility factor. The higher ductility $(\mu)$ capacity, the higher energy absorption, and consequently the amount of behavior factor will be larger. $\mathrm{R} \mu$ and $\mu$ depend on various factors, such as the type of materials, period of system alternation, damping of system, the type of loading, the load-deformation model, P- $\Delta$ effects and the backrest (soil type). According to Figure 1 the ductility factor of total structure $\mu$ is defined to maximum relative lateral displacement $\Delta \max$ to the lateral displacement of relative yield $\Delta y$ as:

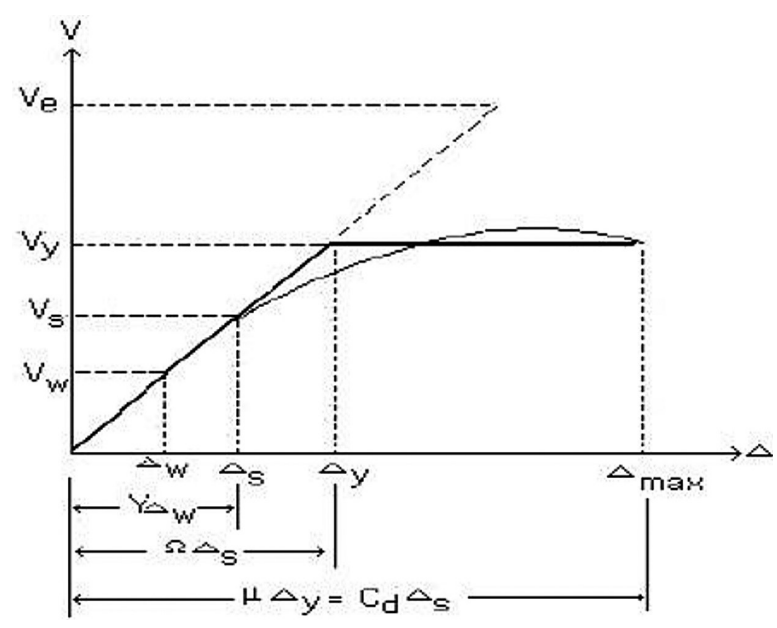

Fig. 1. The general behavior of a conventional structure

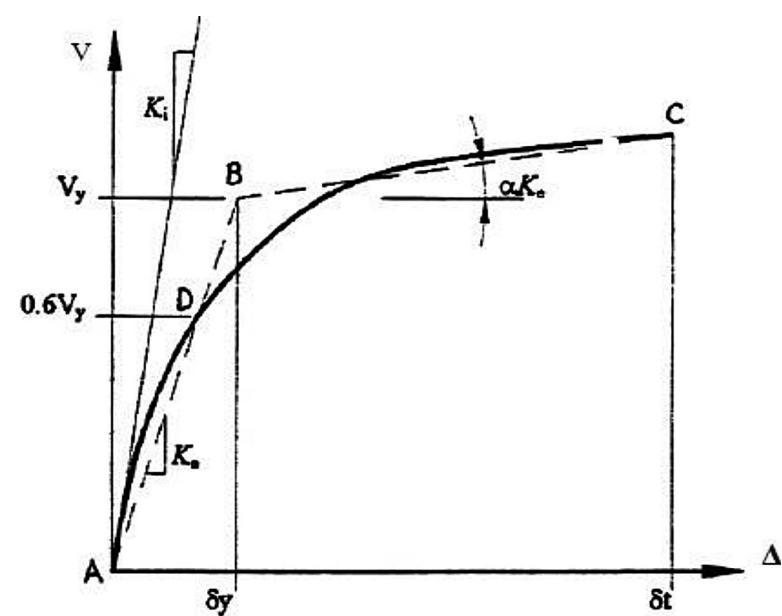

Fig. 2. Pushover curve and the model of two linear behaviors

$$
\mu=\frac{\Delta_{\max }}{\Delta_{y}}
$$

The relationship between $R \mu$ and $\mu$ has been studied by many researchers including the protocol ATC-19 which recommended the methods by Niyomark and Hall, Kravinkler and Nesar, Miranda and Bortru. Each of the mentioned methods is summarized in the following sections.

Niyomark and Hall method. Niyomark and Hall, according to the main alternation periods of structure $(T)$, provided the following formula to determine the reduction factor:

$$
\begin{array}{ll}
R_{\mu}=1 & T \leq 0.03 \mathrm{sec} \\
R_{\mu}=\sqrt{2 \mu-1} & 0.12 \leq T \leq 0.5 \mathrm{sec} \\
R_{\mu}=\mu & T \geq 1.0 \mathrm{sec}
\end{array}
$$

Kravinkler and Nesar method. Kravinkler and Nesar provided a relationship for systems of a free degree on rocky ground or hard soil. Their suggested relationship changes according to the 
period of structure alternation $(\mathrm{T})$ and load deflection-shift in the secondary part $(\alpha)$.

$$
\begin{gathered}
R_{\mu}=[c(\mu-1)+1]^{\frac{1}{c}} \\
c(T, \alpha)=\frac{T^{a}}{1+T^{a}}+\frac{b}{T}
\end{gathered}
$$

The parameters of $a$ and $b$ for different strain hardening ratio $(\alpha)$ are obtained as follows ( $\alpha=0 \%$ reflects full Elasto-plastic case. For different values of $\alpha$ can use linear interpolation):

$$
\begin{aligned}
& \alpha=0 \%: a=1.00, \quad b=0.42 \\
& \alpha=2 \%: a=1.00, \quad b=0.37 \\
& \alpha=10 \%: a=1.00, b=0.29
\end{aligned}
$$

Miranda and Borutor method. Miranda and Borutor (1994) summarized therelationships developed by a number of researchers, including Niyomark and Hall, Ridil and Niyomark, and Kravinkler and Nesar. They also expanded the corresponding equations for rocky grounds, alluvial (alluvial) and soft sand. The formula of calculating ductility factor in terms of alternation period of structure and location of the building is as follows:

$$
R_{\mu}=\frac{\mu-1}{\Phi}+1
$$

- For rocky grounds:

$$
\Phi=1+\frac{1}{10 \mathrm{~T}-\mu \mathrm{T}}-\frac{1}{2 \mathrm{~T}} e^{-105(\ln (\mathrm{T})-0.6)^{2}}
$$

- For alluvial grounds:

$$
\Phi=1+\frac{1}{12 \mathrm{~T}-\mu \mathrm{T}}-\frac{2}{5 \mathrm{~T}} e^{-2(\ln (\mathrm{T})-0.2)^{2}}
$$

- For soft soil grounds:

$$
\Phi=1+\frac{\mathrm{T}_{g}}{3 \mathrm{~T}}-\frac{3 \mathrm{~T}_{g}}{4 \mathrm{~T}} e^{3\left(\ln \left(\mathrm{T} / \mathrm{T}_{g}\right)-0.25\right)^{2}}
$$

where: $\mathrm{T}_{g}-$ is the alternation period of accelerogram dominant.

The main alternation period. The main alternation periods in steel moment frames, steel plate shear walls and buckling restrained braced according to the formula of regulations that is below, were calculated. For steel moment frames:

$$
T=0.05 H^{0.75}
$$

To frames of steel plate shear walls and buckling restrained braces:

$$
T=0.08 H^{0.75}
$$

\section{Factor of increasing resistance}

The design regulations, structures are designed in such a way that none of them exceeds the elastic stage, otherwise the plastic hinge will be formed in them. As a result, the overall hardness of the structure is reduced, but the structure will be able to resist till the hinges formation caused to create mechanism and structure hardness conducted toward zero. At this point if the ductility capacity is reached to end, the structure will be destroyed. Structures during the process will bear additional resistance that are not considered at the initial design of structure and are known as the factor of increasing resistance. This factor, according to the following formula is, corresponding force with the total surrender of structure $\left(V_{y}\right)$, corresponding force with formation of the first plastic hinge in structure $\left(V_{s}\right)$ :

$$
\Omega=\frac{V_{y}}{V_{s}}
$$

The factor of increasing resistance is indicative of several factors. One of them is the degree of structure uncertainty that provides the possibility of members' internal forces playback in case of losing resistance to other members. The more uncertain the structure, the higher the value of factor. Strain hardening is also a factor that causes an increase in resistance after surrender of members and thus increases the resistance of the whole structures. Resistances of the above defined limit of consumed materials are another reasons that in laboratory research cause to increase this factor.

\section{Allowable stress factor}

This factor, according to the regulations dealing with design stresses (allowable load or end load) is determined and its value is the ratio of force in the formation of the first plastic hinge $\left(V_{s}\right)$, to force the allowable stresses $\left(V_{w}\right)$. In the ATC-19 (Bortur and Witaker) based on earthquake-resistant frames, the values are expressed for allowable stress factor in Table 1.

Table 1. Proposed allowable stress factor ATC-19 (Bortur and Witaker)

\begin{tabular}{|c|c|}
\hline The number of frame openings & Allowable stress factor $(\mathrm{Y})$ \\
\hline 2 & 0.71 \\
\hline 3 & 0.86 \\
\hline 4 & 1.00 \\
\hline
\end{tabular}




\section{THE EXPERIMENTAL MODEL OF CAMEROON BLACK FOR BUCKLING RESTRAINED BRACE}

To validate the finite element model of buckling restrained brace, the test sample 1-99 Cameroon Black was selected as it was also tested at the University of California, Berkeley [8]. The selected profile of the sample model was used. In Figure 3 and 4 respectively, you can observe a view of test sample and the details of the test sample 1-99.

The above-mentioned sample based on nearfield sample loading of SAC regulations presented in Figure 5 has been tested.

\section{LABORATORY MODEL FOR STEEL PLATE SHEAR WALL}

Draiver et al. [10], tested one sample of 4-floors steel plate shear wall with large-scale according to Figure 6. After modeling it has been under Pushover analysis $[9,10]$. In the sample modeling, the specifications provided in Table 2, according to the researchers, were used. Figure 7 shows a hysteresis curve obtained for the mentioned test sample and also determined load from finite element analysis by the researchers.

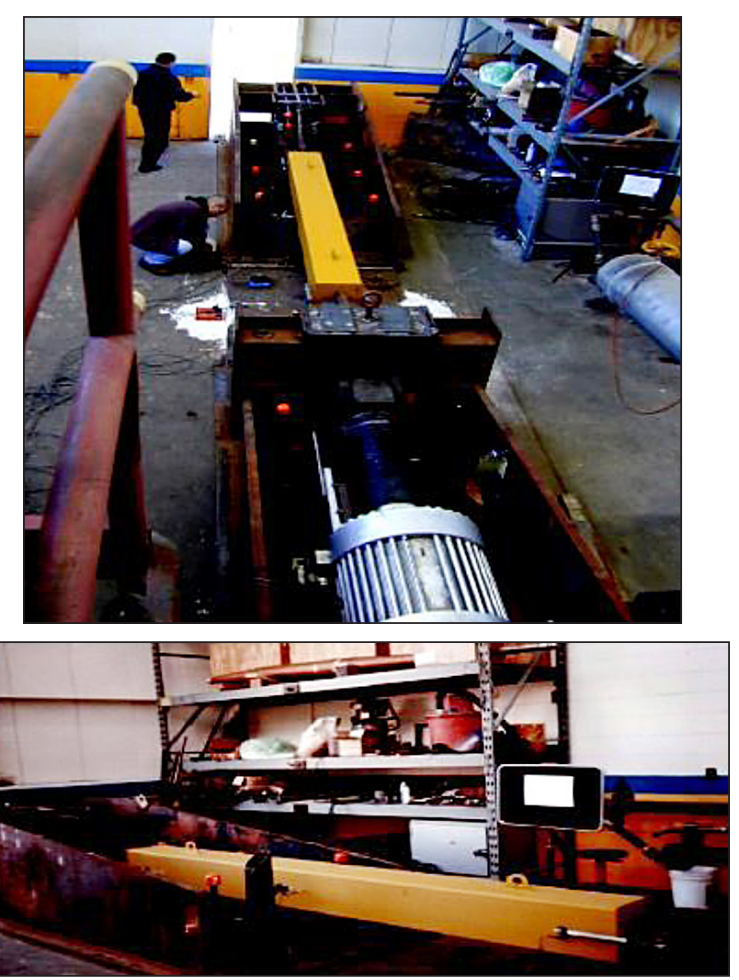

Fig. 3. Buckling restrained braced test sample at UC Berkeley [8]

\section{THE CHARACTERISTICS OF FINITE ELEMENT MODEL}

\section{Geometry and primary conditions}

To create finite element models of steel plate shear wall and buckling restrained brace, the used characteristics in laboratory work of Draiver et al. and Cameroon Black and colleagues are used. The results of finite element analysis were com-

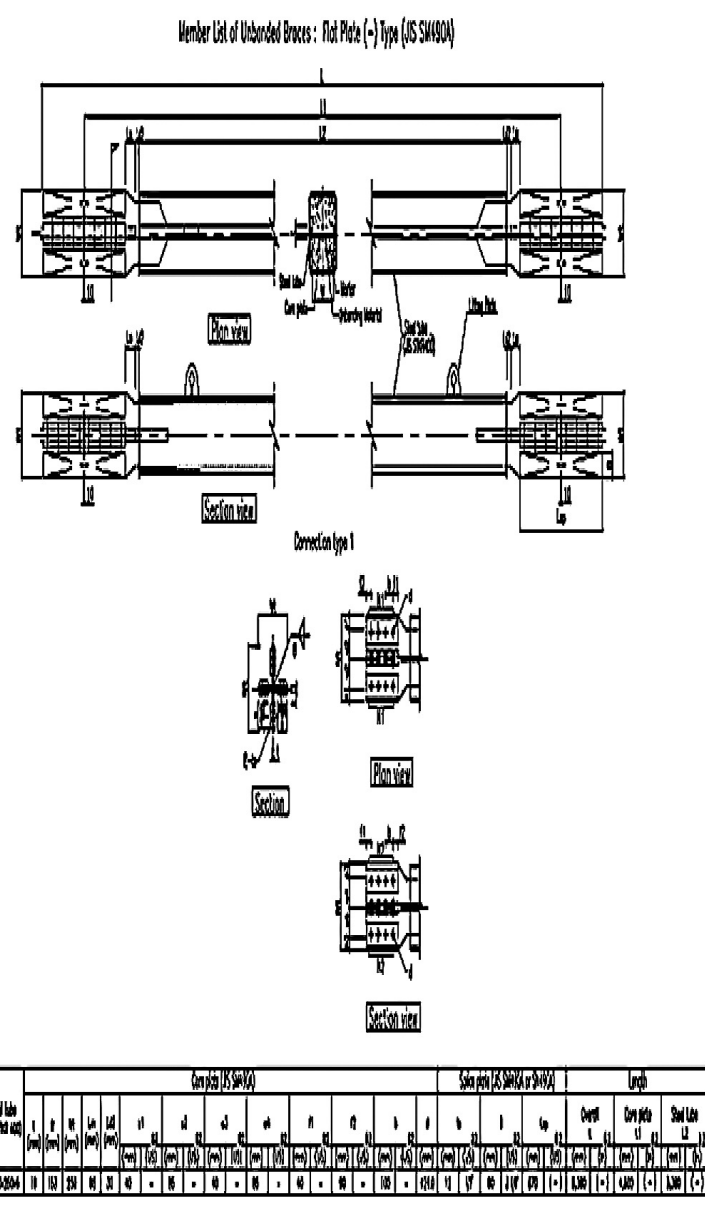

Fig. 4. Details of test sample 1-99 UC Berkeley [8]

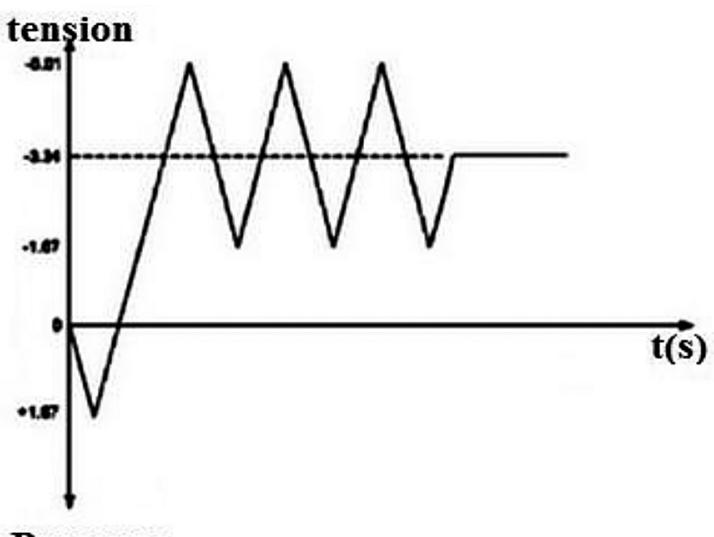

Pressure

Fig. 5. Loading of near-field SAC regulations [8] 
Table 2. Test sample materials characteristics of Draive and colleges 1997

\begin{tabular}{|c|c|c|c|c|c|c|c|c|}
\hline Member & \begin{tabular}{c|} 
Modulus of \\
elasticity (MPa)
\end{tabular} & $\begin{array}{c}\text { Static yield } \\
\text { stress (MPa) }\end{array}$ & $\begin{array}{c}\text { Final static } \\
\text { stress (MPa) }\end{array}$ & $\begin{array}{c}\text { Breaking } \\
\text { stress (MPa) }\end{array}$ & $\begin{array}{l}\text { The final } \\
\text { strain (\%) }\end{array}$ & $\begin{array}{l}\text { Hardening } \\
\text { strain }(\%)\end{array}$ & $\begin{array}{l}\text { The final } \\
\text { strain }(\%)\end{array}$ & $\begin{array}{l}\text { Breaking } \\
\text { stress (\%) }\end{array}$ \\
\hline Panels 1 \& 2 & 208800 & 341 & 456 & 376 & 0.175 & 2.62 & 20.1 & 34.2 \\
\hline Panel 3 & 210900 & 257 & 344 & 277 & 0.134 & 2.44 & 20.0 & 42.5 \\
\hline Panel 4 & 203100 & 262 & 375 & 303 & 0.145 & 1.53 & 17.7 & 34.1 \\
\hline W $310 \times 118$ & 203000 & 313 & 482 & 402 & 0.169 & 1.41 & 15.5 & 26.3 \\
\hline W $310 \times 60$ & 203900 & 332 & 478 & 431 & 0.191 & 1.76 & 16.8 & 26.2 \\
\hline W $530 \times 82$ & 206100 & 349 & 493 & 421 & 0.204 & 1.85 & 15.5 & 26.9 \\
\hline Panels $1 \& 2$ & 208800 & 341 & 456 & 367 & 0.175 & 2.62 & 20.1 & 34.2 \\
\hline Panel 3 & 210900 & 257 & 344 & 277 & 0.134 & 2.44 & 20.0 & 42.5 \\
\hline
\end{tabular}

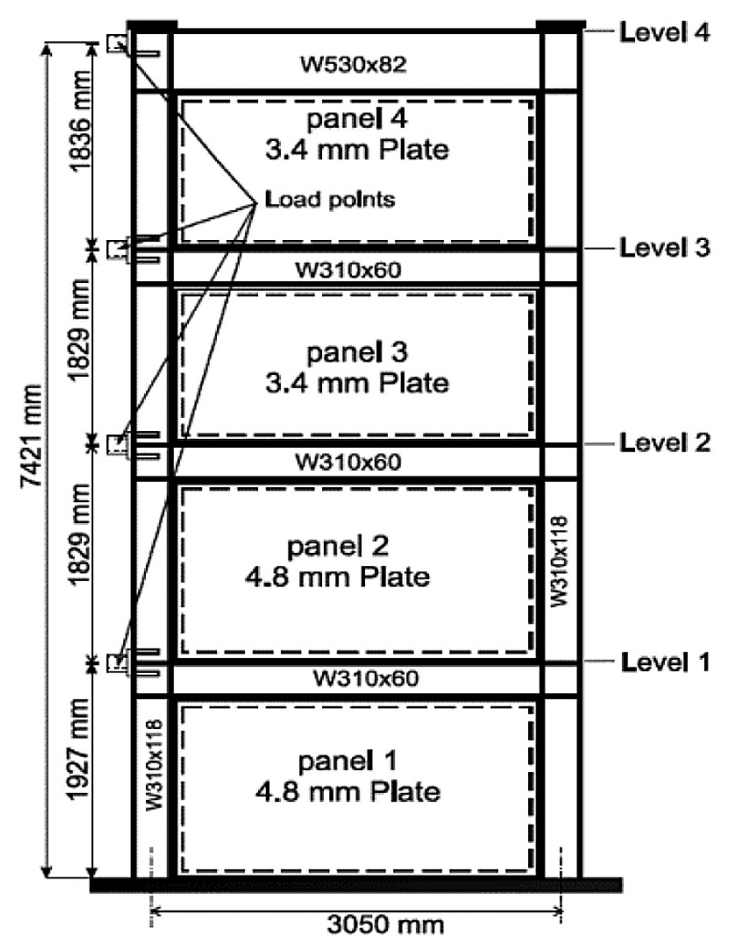

Fig. 6. Test sample of 4 floors [9] pared with test results. In the analytical models, the moving of frames in the direction of perpendicular to the plate has been blocked. Buckling restrained braced geometric model in Abaqus program can be observed in the Figures $8 \mathrm{a}$ and $8 \mathrm{~b}$.

Geometry of 4 floors steel plate shear walls with finite element meshing is shown in Figure 9.

The border members as well as the steel plate shear walls thickness of 4 floors with perforated plates is similar to steel plate shear wall sample of the designed 4-floors with a minimum application thickness of $3 \mathrm{~mm}$ that the holes with a diameter of $60 \mathrm{~cm}$ by $100 \mathrm{~cm}$ center distance is created in them. The full finite element model of 4-floors steel plate shear wall with perforated plates can be seen in Figure 10.

In the program of Abaqus when a page placed under perpendicular load to the edge of its shell, if the load is applied without eccentricity or plate is completely flat and without defect, no buckling creates in it. Therefore, after analyzing the buckling, the sample of buckling restrained brace under presented loading in Figure 5, the first model

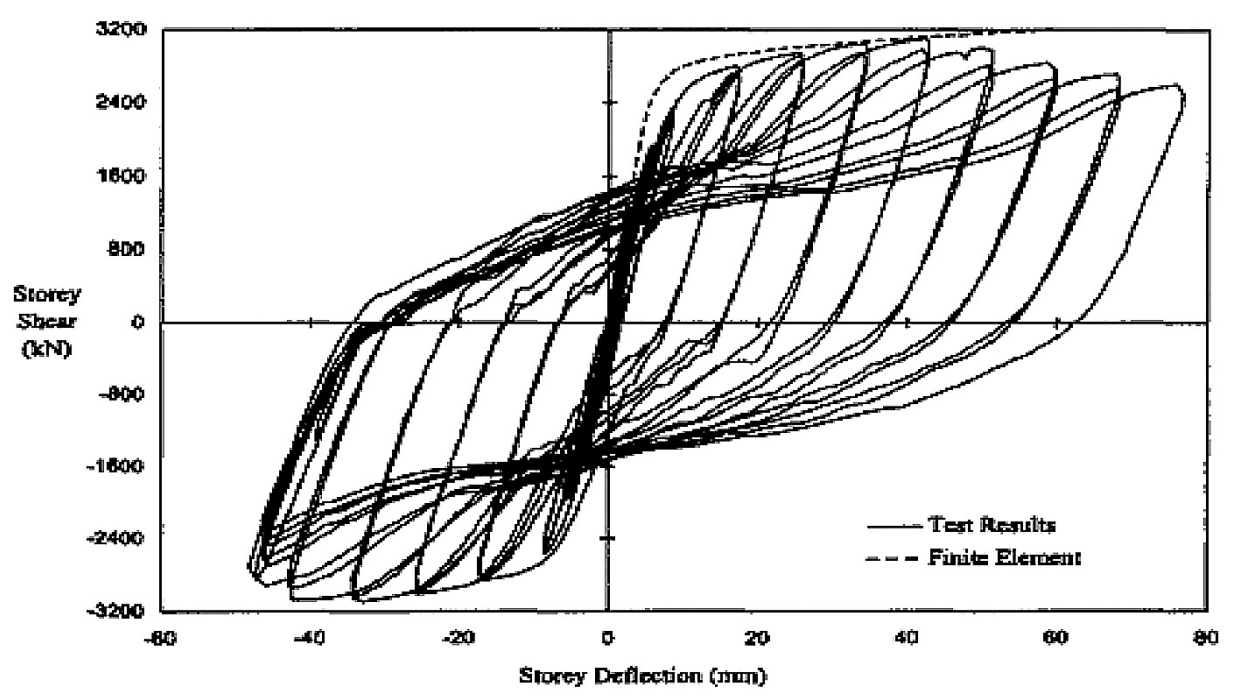

Fig. 7. Hysteresis curve of test and Pushover obtained of finite element analysis of Draiver et al. [11] 
a)

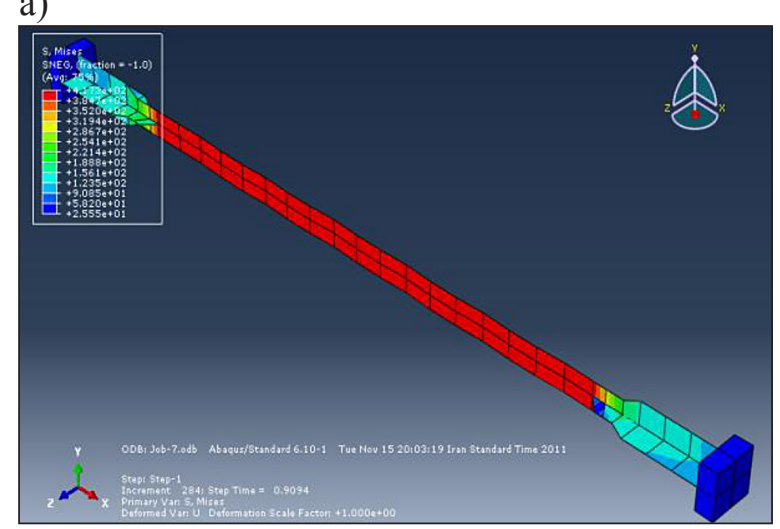

b)

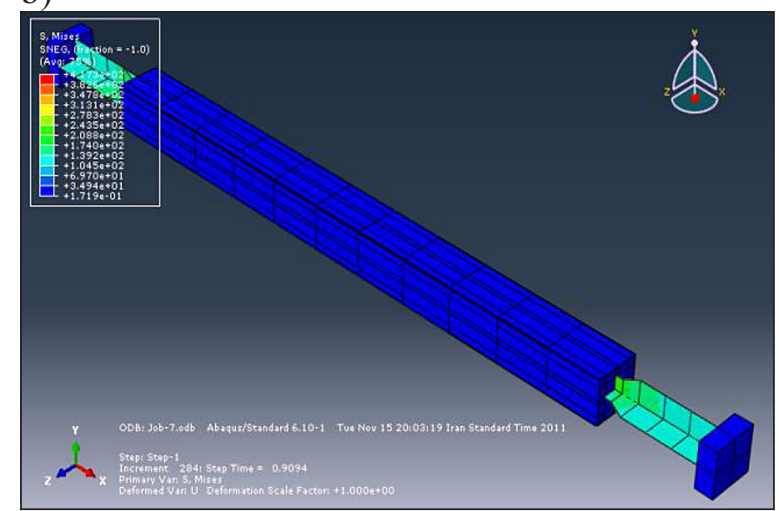

Fig. 8. a) Finite element model of test sample with sheath; b) Steel core of finite element model the test samples

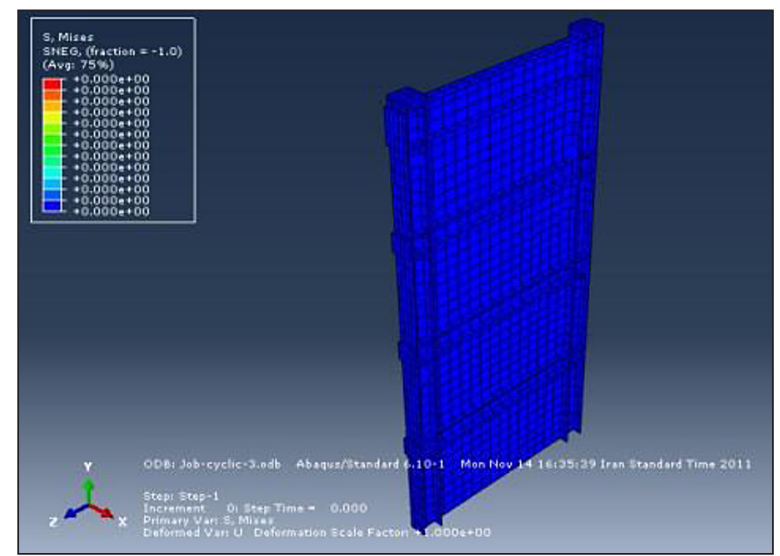

Fig. 9. Geometry and finite element model meshing of a 4-floors sample, Driver and colleges (1997)

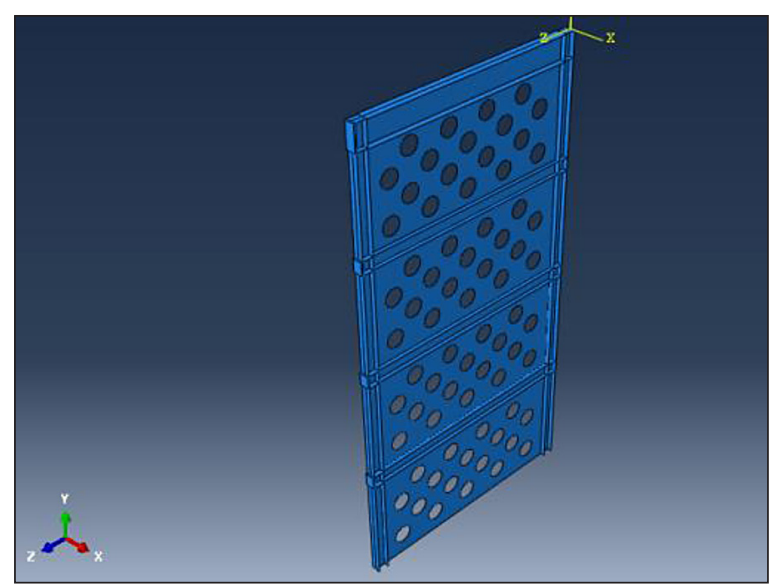

Fig. 10. Finite element model of 4-floors steel plate shear wall with perforated pages

of buckling is used in order to introduce the buckling to the program.

There were also some primary defects in the pages of all test samples of steel plate shear walls, whose defects are created with different reasons such as welding operations of filler plates to beams and columns, floor beams moment deformations and eccentricity of the connecting ropes.
These defects can have a significant impact on the behavior of steel plates.

So the primary defects of filler plate were considered in finite element model. Primary defect pattern for filler plate is considered according to the loaded shear wall buckling modes with the same procedure that was used in the related test. In this way by analyzing the buckling, buckling modes with a range of $\mathrm{w} 2$ ( $\mathrm{w}$ is the thickness of page) were selected as primary defects. In buckling restrained brace for primary defect definition, the first model of buckling was used.

In the steel plate shear walls, beams, columns and filler plates are modeled and in buckling restrained brace of central steel (steel core and hardenings of elastic area) using 4-node shell elements with a double curve and reduced integral (ABAQUS element S4R) are modeled. Concrete and braced steel sheath is modeled as SOLID. S4R element calculates axial shell strains and great rotations. The elements in each point have six degrees of freedom. In the main coordinate system, three degrees of transitional freedom (ux, $\mathrm{uy}, \mathrm{uz})$ and three degrees of rotation freedom $(\theta \mathrm{x}$, $\theta y, \theta z)$ are defined. S4R element is based on an ISO parametric formula. In order to form the internal force vector is used a point integral on the middle level of the element.

In this study the reduced integral elements are used, because they offer more accurate results, and if the elements are not locally deformed, largely runtime will reduce. Element size is selected by investigating the mesh refining. For modeling of the separated material between the steel core and the surrounding concrete, a contact is used with very low friction tangential factor (about 0.001 ) due to the role of the material that its main task is the prevention of shear force transmission between the core and concrete. As 
well as for transmission of force from core to the sheath surrounding it A hard contact is also introduced therein. The empty space between the core and bracing, due to expanding core in pressure for it, is considered here as a distance of $3 \mathrm{~mm}$ in line with core width and $5 \mathrm{~mm}$ in line with thickness of the core has been used.

\section{Material characteristics}

The stress responses against determined strain, stretching tests of coupon as well as the standard of Von Mises are used. To determine the plastic strain increase, also the current law was used. In all analyzes of uniform Pushovar, a nonlinear model, isotopic and harden are used. This model is suitable for uniform loading. In alternation loading of quasi-static and earthquake loading that contain a lot of tension and shear actions, Bauschinger impact is important. Therefore, in the analysis of the two types of loading, the kinematic hardening law was used. Concrete and steel sheath collection in buckling restrained brace sample is modeled as elastic and plastic behavior for them is not defined. For the rest of the elements of buckling restrained brace, elastic behavior is considered.

\section{VALIDATE THE FINITE ELEMENT MODELS WITH LABORATORY RESULTS}

In Figure 11, load-displacement graph obtained of the testing and analysis of Cameroon Black et al. and finite element analysis (FEM) was shown. In Figure 12, load-displacement graph obtained of the testing of Draiver et al. and FEM analysis was presented. It can be seen that the obtained results of presented finite element models in this paper are in good accordance with the results of laboratory samples.

\section{RESULTS OF FEM ANALYSIS}

Pushover graphs with two leaner graphs of 4-floors steel moment frame (MF-4), 4-floor steel plate shear walls with a thickness of $1 \mathrm{~mm}$ (SPSW-4 - $1 \mathrm{~mm}$ ), 4-floors steel plate shear wall with perforated pages (SPSW-4 - perforated), 4-floors steel plate shear wall with a minimum application thickness of $3 \mathrm{~mm}$ (SPSW-4 - $3 \mathrm{~mm}$ ) and 4-floor buckling restrained brace (BRB-4) are shown in the Figures of 13 to 17.

After determining the relative displacement of surrender from the two linear graphs and determining the ductility factor of the formula (2), ductility reducing factor is determined with Niyomark and Hall method. To calculate the factor of resistance increase according to formula (17), it is assumed that the forming location of the first plastic hinge is the moment of separation of real curves and two linear after the elastic area (start yielding) or the first point their contact. The allowable stress factor value according to Table 1 for all samples is assumed as 1. Finally, using formula (1), the behavior factor is calculated. The mentioned parameters in Table 3 are provided.

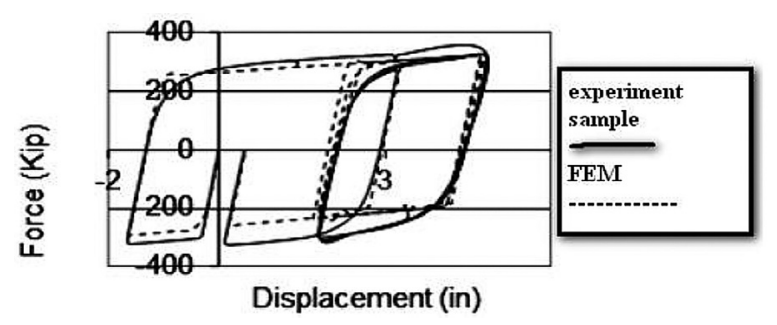

Fig. 11. The force curve - axial displacement of bracing in the testing mode and finite element analysis

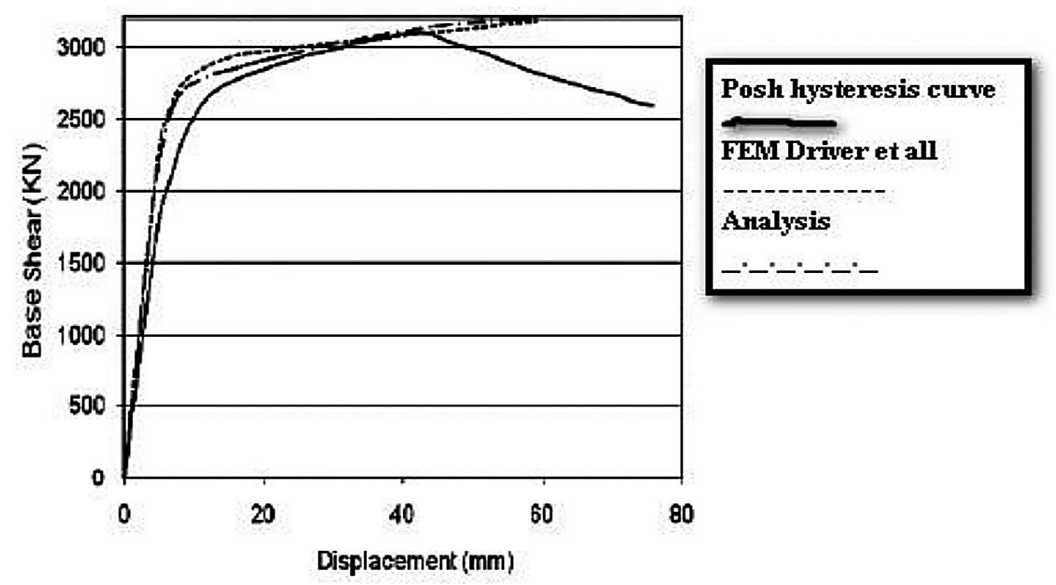

Fig. 12. Comparison of load-displacement graphs obtained of the testing and FEM analysis 


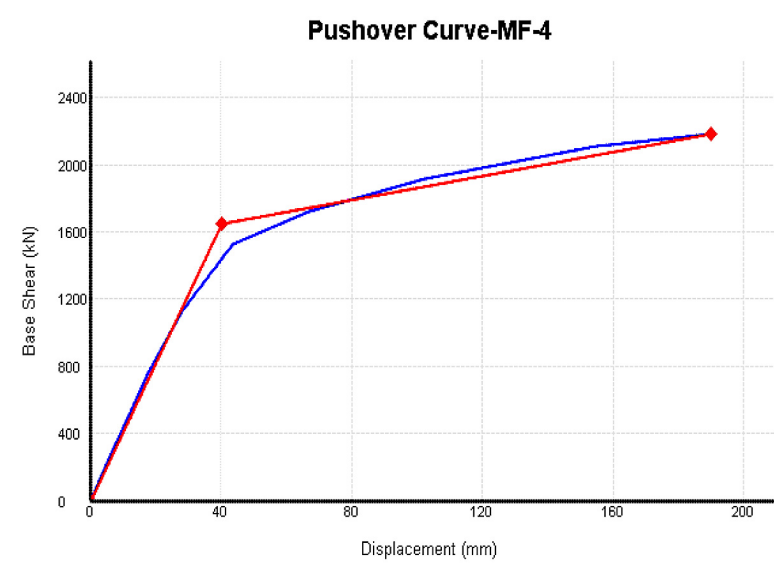

Fig. 13. base shear force graph versus first floor displacement of 4-floors steel moment frame

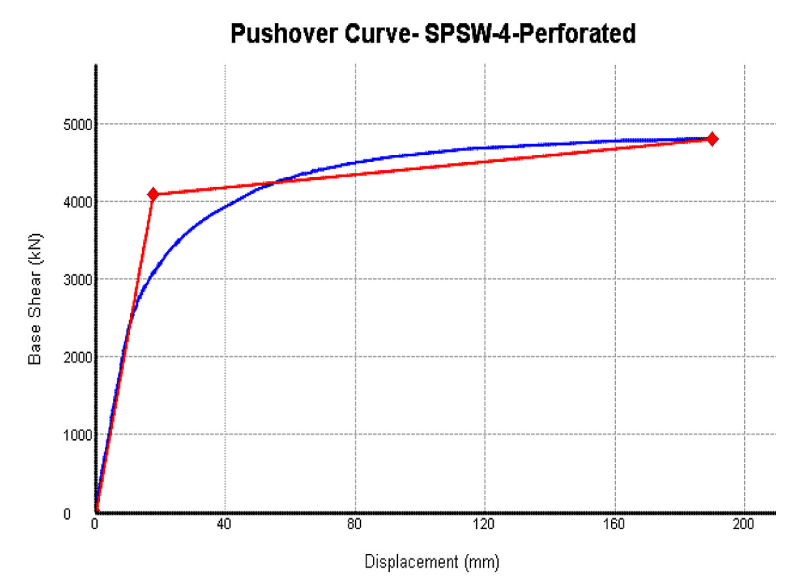

Fig. 15. base shear force graph versus first floor displacement of 4-floors Steel Plate Shear Walls with perforated pages

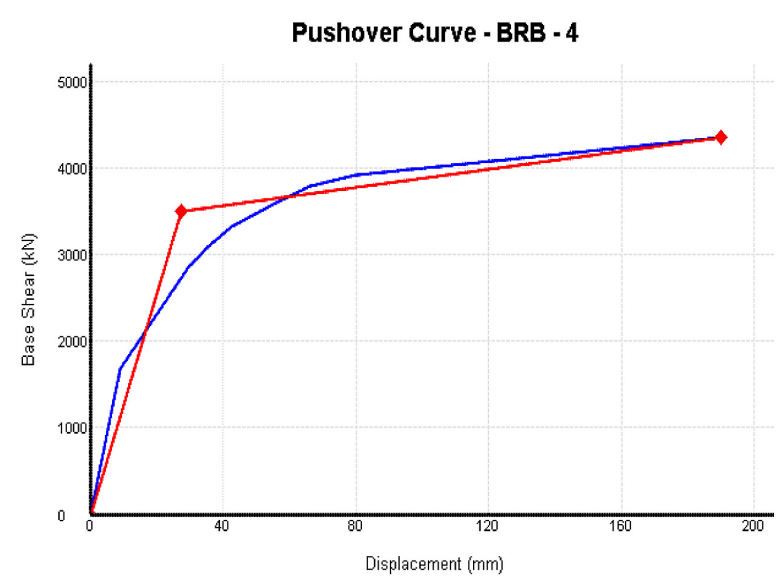

Fig. 17. base shear force graph versus first floor displacement of 4-floors buckling restrained brace

The ultimate strength value $(F u)$, the effective elastic hardness $(\mathrm{Kel})$, the effective elastic hardness $(K v g l)$, hardening factor $(a)$ were determined from two liners graphs and are presented in Table 4. In order to better understanding the obtained val-

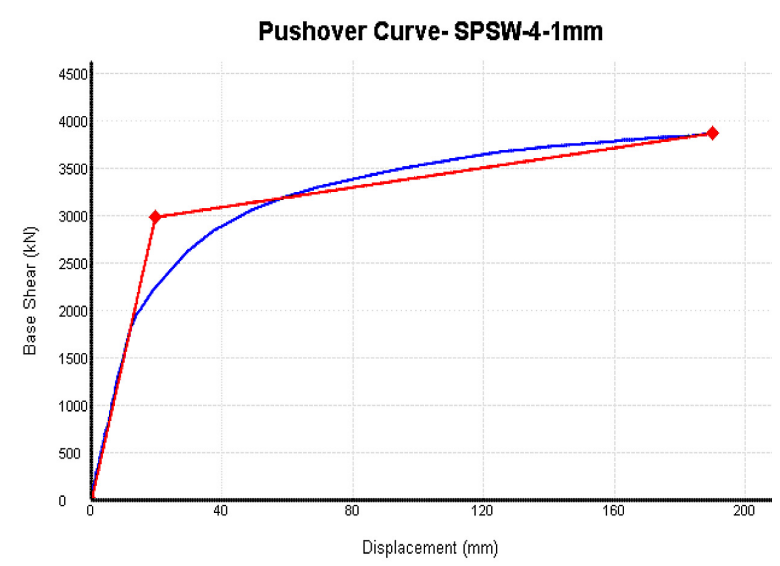

Fig. 14. base shear force graph versus first floor displacement of 4-floors Steel Plate Shear Walls with a thickness of $1 \mathrm{~mm}$

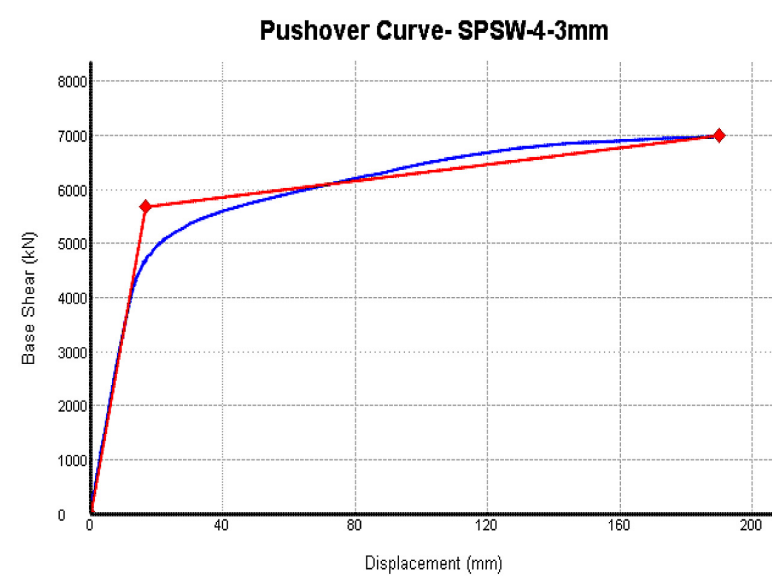

Fig. 16. base shear force graph versus first floor displacement of 4-floors Steel Plate Shear Walls with a thickness of $3 \mathrm{~mm}$

ues, load curves related to frames of 4 floors for the corresponding system is shown in Figure 18. The behavior factor values and ductility factor of the corresponding system were compared in Figure 19. In terms of ultimate resistance the system was compared in Figure 20.

\section{CONCLUSIONS}

The provided numbers in the tables and obtained curves from finite element analysis, the following conclusions can be reached:

Ultimate resistance of steel plate shear wall system even with less thickness from the minimum application thickness is greater than the ultimate resistance buckling restrained brace system and moment frame, so the system is considered more resistant. Ductility of steel plate shear walls even with thickness of less pages from the minimum ap- 


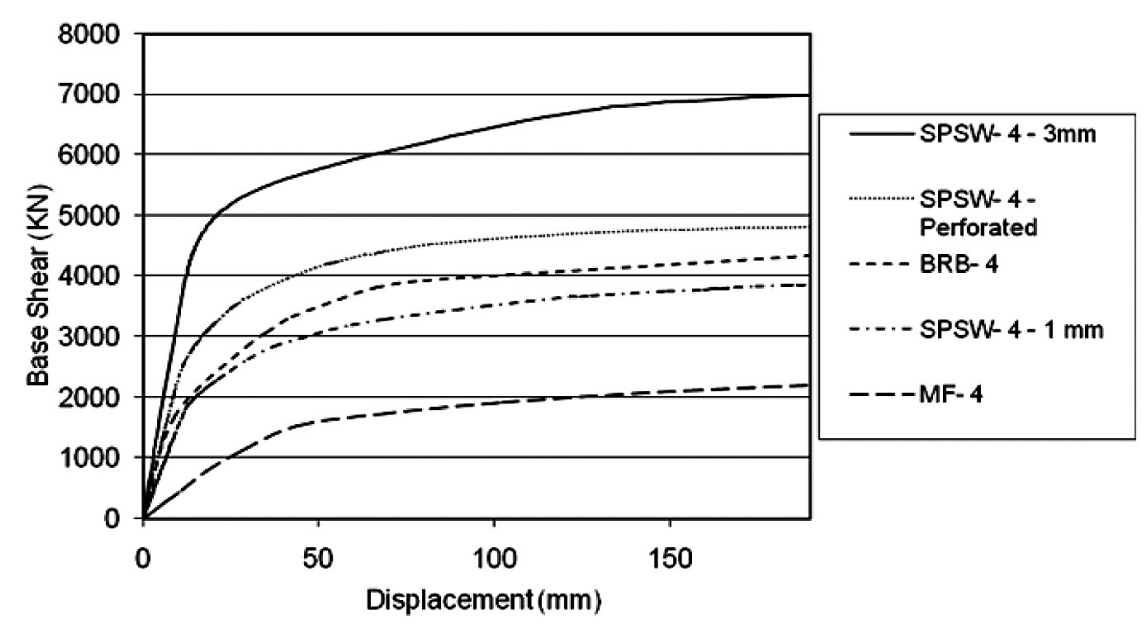

Fig. 18. load-displacement graph of 4-floors frames with different systems

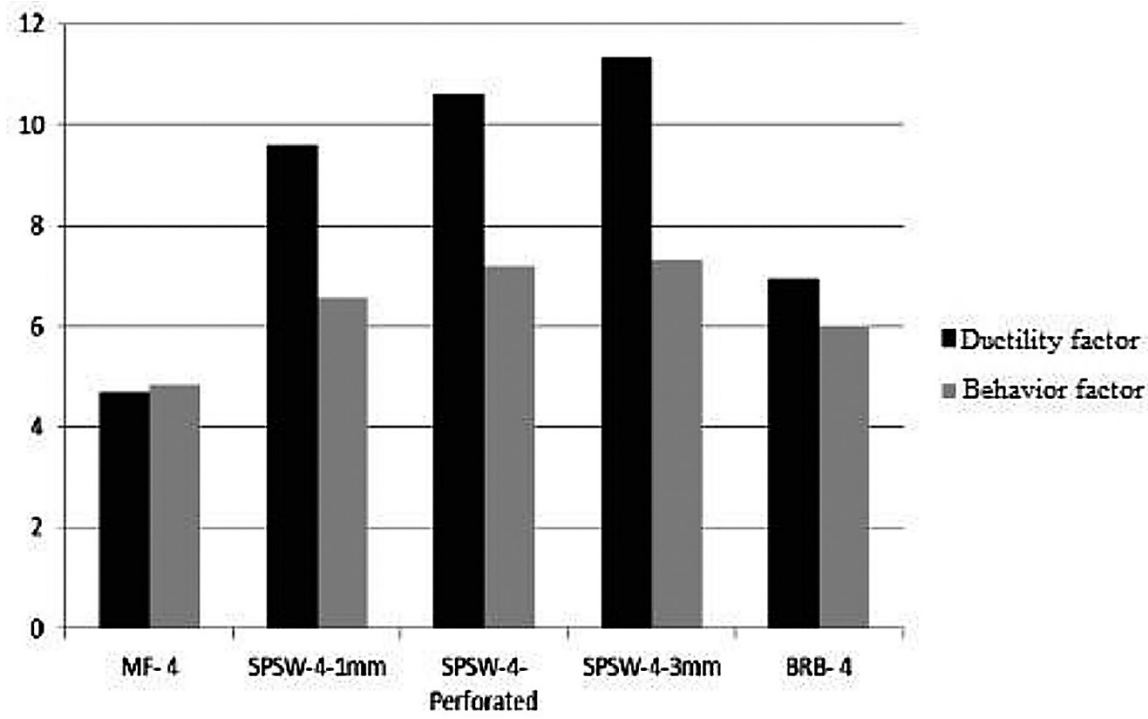

Fig. 19. the ductility factor and behavior factor in the steel plate shear wall, buckling restrained brace and moment frame of 4 floors

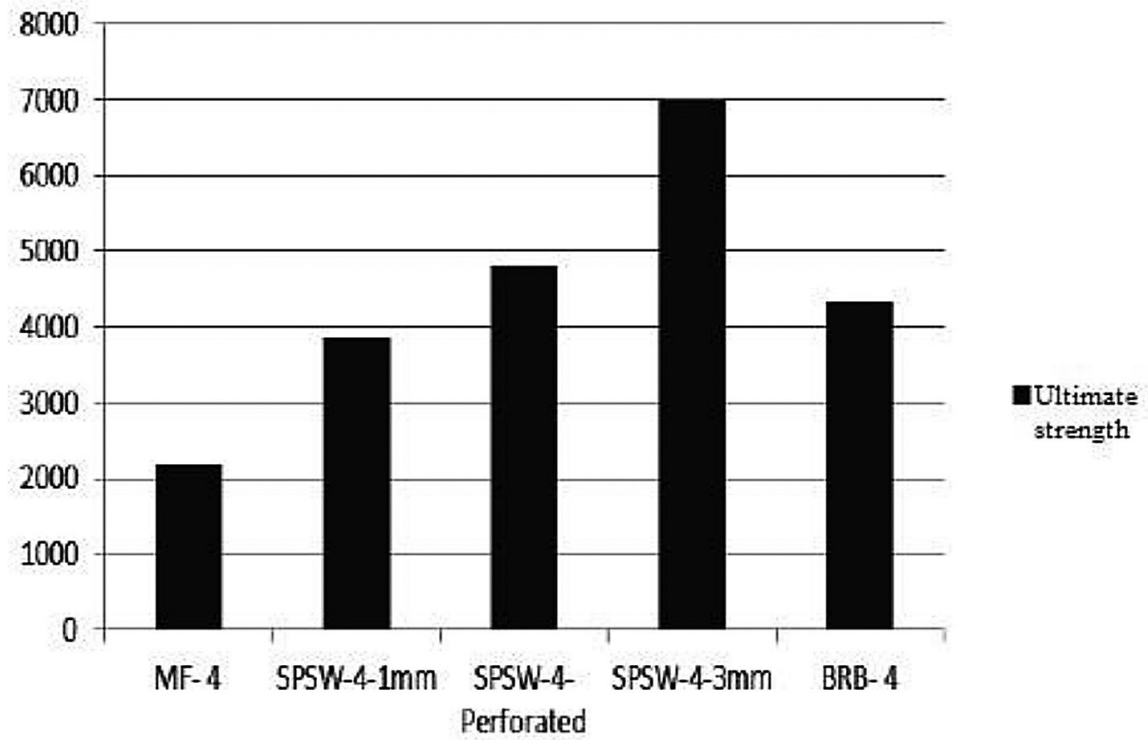

Fig. 20. the ultimate resistance in 4-floors frames of Steel Plate Shear Walls (SPSW), buckling restrained brace (BRB) and moment frame (MF) 
Table 3. Obtained behavior factor parameters of finite element analysis

\begin{tabular}{|l|c|c|c|c|c|c|}
\hline \multicolumn{1}{|c|}{ Samples } & $\mathrm{T}(\mathrm{s})$ & $\mu$ & $\mathrm{R}_{\mu}$ & $\Omega$ & $\mathrm{Y}$ & $\mathrm{R}$ \\
\hline MF-4 & 0.616 & 4.71 & 3.3 & 1.47 & 1 & 4.85 \\
\hline SPSW-4 - 1 mm & 0.385 & 9.60 & 4.3 & 1.53 & 1 & 6.58 \\
\hline SPSW-4 - perforated & 0.385 & 10.60 & 4.5 & 1.60 & 1 & 7.20 \\
\hline SPSW-4 - 3 mm & 0.385 & 11.34 & 4.7 & 1.56 & 1 & 7.33 \\
\hline BRB-4 & 0.385 & 6.93 & 3.6 & 1.67 & 1 & 6.01 \\
\hline
\end{tabular}

Table 4. Obtained hardness and resistance parameters of finite element analysis

\begin{tabular}{|l|c|c|c|c|c|c|}
\hline \multicolumn{1}{|c|}{ Samples } & $\mathrm{K}_{\mathrm{el}}(\mathrm{KN} / \mathrm{mm})$ & $\mathrm{K}_{\text {inel }}(\mathrm{KN} / \mathrm{mm})$ & $\alpha(\%)$ & $\Delta_{\mathrm{y}}(\mathrm{mm})$ & $\mathrm{F}_{\mathrm{y}}(\mathrm{KN})$ & $\mathrm{F}_{\mathrm{u}}(\mathrm{KN})$ \\
\hline MF-4 & 40.93 & 3.58 & 8.75 & 40.40 & 1651.94 & 2187.91 \\
\hline SPSW-4 - 1 mm & 159.00 & 5.20 & 3.47 & 19.83 & 2973.58 & 3858.77 \\
\hline SPSW-4 - perforated & 227.24 & 4.21 & 1.85 & 17.98 & 4088.77 & 4808.29 \\
\hline SPSW-4 - 3 mm & 338.20 & 7.61 & 2.25 & 16.75 & 5666.18 & 6984.62 \\
\hline BRB-4 & 128.12 & 5.16 & 4.03 & 27.42 & 3512.30 & 4351.83 \\
\hline
\end{tabular}

plication thickness is more than the buckling restrained brace and moment frame. So the energy dissipation of this system is more in earthquake.

Factor of resistance increase in the system of buckling restrained brace is more than a system of steel plate shear wall that the ratio of yield resistance to corresponding resistance is with the first plastic hinge formation. In other words, the safety margin of using steel plate shear walls is more similar to the system of BRBs and in terms of design, the system is more reliable.

Behavior factor of steel plate shear wall systems, even with a thickness of fewer plates from the minimum application thickness, is more restrained than buckling braced systems and moment frame. So the basic sheer level in structure design with steel shear wall system is less than buckling restrained brace system and moment frame. So the structure design with steel plate shear wall system would be more economic.

Given that in the short and medium buildings, the required thickness to design is less than the minimum application thickness of $3 \mathrm{~mm}$, use of steel plate shear walls with solid plates are more suitable for high-rise buildings and, since the beam and columns must be able to develop the created stretch on the plate, use it with a minimum application thickness in the short and medium buildings will cause to increase the beam and column points.

A suitable solution is the use of steel plate shear wall with perforated plates that here 4 floors steel plate shear wall with a thickness of
$3 \mathrm{~mm}$ and perforated plates is analyzed with a regular pattern and the results show, however, that hardness and ultimate resistance of this system is less than steel plate shear wall with solid plates, but its ductility and behavior factor is slightly lower and for the development of the created stretch area in the plate need to lighter points than solid state. In addition, present the openings is considered an advantage to the solid plates. The results showed that the hardness and ultimate resistance, ductility and behavior factors of such a steel plate shear walls are higher than BRBs system.

\section{REFERENCES}

1. Thorburn L.J., Kulak G.L. and Montgomery C.J. Analysis of steel plate shear walls. Structural Engineering Report No. 107, Dept. of Civil Engineering, University of Alberta, Edmonton, AB. 1983.

2. Roberts T.M. and Sabouri-Ghomi S. Hysteretic characteristics of unstiffened perforated steel plate shear panels. Thin Walled Structures, 14, 1992, 139-151.

3. Wada A., Connor J., Kawai H., Iwata M. and Watanabe A. Damage tolerant structure. Proceedings of Fifth us Japan Workshop on the Improvement of Building Structural Design and Construction Practices, Redwood City, California, 1992, 27-39.

4. Sabelli R. and Aiken I. U.S. building-code provisions for buckling restrained braced frames, basis and development. In: Proceedings of the $13^{\text {th }}$ World Conference on Earthquake Engineering, Vancouver, B.C., Canada, Paper No. 1828, 2004.

5. Bhowmick A.K. Seismic analysis and design of steel plate shear walls. A thesis submitted to the 
Faculty of Graduate Studies and Research in partial fulfillment of the requirements for the degree of Doctor of Philosophy in Structural Engineering, Department of Civil and Environmental Engineering, Edmonton, Alberta. 2009.

6. Zahraiy-Eftekhari M. Determine the slimy damping factor equal braced frames with brace BRB based on nonlinear static analysis (Pushover). Tehran University, 2006.

7. Uang C.M. Establishing R (or Rw) and Cd factors for building seismic provisions. Journal of Structural Engineering, ASCE, 117(1), 1991, 19-28.

8. Black C., Makris N. and Aiken I. Component testing, stabillity analysis and characterization of buckling restrained braces. Final Report to Nippon Steel Corporation, 2002.

9. Driver R.G., Kulak G.L., Kennedy D.J.L. and Elwi A.E. Seismic behaviour of steel plate shear walls. Structural Engineering Report No. 215, 44 Dept. of Civil and Environmental Engineering, University of Alberta, Edmonton, AB. 1997.

10. Driver R.G., Kulak G.L., Kennedy D.J.L. and Elwi A.E. Cyclic test of four storey steel plate shear wall. Journal of Structural Engineering, ASCE, 124(2), 1998, 112-120.

11. Driver R.G., Kulak G.L., Elwi A.E. and Kennedy D.J.L. FE and Simplified models of steel plate shear wall. Journal of Structural Engineering, 124(2), 1998, paper No. 15675. 